\title{
El discurso de la fidelidad durante la Guerra de Sucesión
}

\author{
I. M. VICENT LÓPEZ *
}

\begin{abstract}
RESUMEN
ABSTRACT

Este ensayo examina la centralidad de This essay examine the centrality of la fidelidad, en el reinado de Felipe $V$, sobre todo, durante sus primeros años. Muestra como la cultura política de corte confesional y el lenguaje moral que llevaba aparejado dominó el discurso político en Castilla durante la Guerra de Sucesión en España. fidelity to Philippe V's kingship, overall, during its first years. It shows how the confessional political culture and its moral language dominate the political discourse in Castile during the War Succesión in Spain.
\end{abstract}

"Aviendo persuadido los dos Papeles antecedentes la necesidad, en que impone a los Españoles, las inviolables leyes de la Conciencia, la Religión, y la Honra de mantenerse en el justo dominio de el Señor Phelipe V. Intenta persuadir esto mismo la Coriveniencia, y el interés político ...se dirige este discurso, con menos eloquencia, a fin de que el infausto libertinaje en la obediencia de su legítimo Dueño, que no acaba de rendirse a la rigurosa ley de Conciencia, al preciso cuydado de la Religión, y al heroyco precepto de la honrra, ceda siquiera a el amor propio de las utilidades materiales de cada uno",

Desengaño Político, conveniencia e interés, DIDF [Don Juan de Ferreras] impreso, 1711, p. 1.

\footnotetext{
* Departamento Historia Moderna, UAM.
} 
"...el Omenage y Juramento de fidelidad que son los dos estrechos vínculos con los quales las leyes de el Cielo y de la Tierra forman nudo indisoluble".

Carta responsiva de el Rey nuestro Señor Don Phelipe Quinto a el Breve del Papa en 18 de junio de 1710; BN Mss. 11267/14, fol. $1 \mathrm{v}$.

Las peculiares circunstancias que concurrieron en Castilla durante la Guerra de Sucesión, situaron a la fidelidad como fenómeno y como concepto en el centro de la acción política. Desde el momento en que los aliados declararon la guerra a Luis XIV, y especialmente desde que comenzaron a ocupar distintas plazas de la Península Ibérica. El principal problema político para ambos contendientes fue determinar el grado de fidelidad que Felipe $V$ concitaba entre sus vasallos castellanos para justiicar la continuación del esfuerzo bélico en la Península o abandonarlo. La defección del Almirante de Castilla en $1702{ }^{1}$ y el apresamiento del marqués de Leganés tres años después ${ }^{2}$, sólo eran los dos casos más señalados del creciente descontento que existía entre las elites hacia el gobierno francés que tutelaba al nuevo monarca, y que multiplicó sus encontronazos en la Corte, sin que ello significara en muchos casos una actitud hostil hacia el propio monarca, sujeto paciente del drama ${ }^{3}$. Al ambiente de mutua desconfianza que reinaba en la Corte de Madrid habia que sumar aún, alguna que otra conspiración contra la sucesión francesa descubierta en el sur de la Península. Estos casos y noticias alentaron a los aliados a confiar en que sus incursiones habrían de encender una rebelión general contra el nuevo gobierno francés, al mismo tiempo que alimentaron, aún más, la desconfianza que este ya venía manifestando desde el principio respecto de los principales personajes de la Monarquía ${ }^{4}$. Las tomas de Gibraltar y la posterior ocupación del Reino de Valencia y el Principado de Cataluña por los aliados convirtieron la fidelidad de los castellanos a su nuevo rey, en la máxima preocupación de su gobierno. Como escribió la Princesa de los Ursinos «es una verdad incontestable que no se entregó esta nación a un principe francés sino a causa

Fernandez Duro. C., El último Almirante de Castilla, Don Juan Tomás Enríquez de Cabrera. Madrid, 1902.

2 Baudrillart, A., Philippe $V$ et La Cour de France. París, 1890, I, p. 230. Kamen, H., La guerra de Sucesión en España, 1700-1715. Barcelona, 1974, pp. 110. MARQUÉs de SAN FELIPE, Comentarios de la guerra de España e Historia de su Rey Felipe V el Animoso. Madrid, 1957. p. 102.

3 El conde de Eril implicado en una conspiración descubierta en Granada en 1704 se defendió diciendo que él era "muy fiel vasallo de Su Majestad, pero los franceses son unos perros", en Kamen, H., Felipe V, el Rey que reino dos Veces. Madrid, 2000, p. 41.

4 En 1705 el gobierno a iniciativa de Amelot liegó a exigir un juramento especial de fidelidad a los grandes, que confirmaba la desaparición efectiva de la confianza y familiaridad propia de la Corte, y la introducción de una nueva estrategia disciplinar en su gobierno. 
del temor que tenía de que no la socorriese lo bastante el emperador ...luego como la mayor parte de Europa se declaró por el archiduque ernpezaron los franceses a no gozar de seguridad en Madrid» ${ }^{5}$. El juicio a fuer de pesimista era acertadísimo en lo que se refería a los motivos últimos que habían decidido a los castellanos a inclinarse en favor del candidato francés ${ }^{6}$.

El panorama sobre el que produjeron los abundantes panfletos, escritos y bandos que pretendian mover la voluntad de los castellanos en favor de uno u otro candidato durante la guerra era confuso, no sólo por la indecisión en que parecía moverse la misma, sino también por la ambigüedad que adoptaron los personajes que representaban la voluntad política del territorio o la encarnaban en la corte, sobre todo para los atentos ojos de los aliados: los prelados y los Grandes. Pero también por la actitud de Felipe $V$ que lejos de comprometerse desde un comienzo por el respeto a las instituciones y sujetos que conformaban el Reino y su gobierno, intento primero mediante el compromiso y más tarde haciendo uso del principio dinástico mediante un lenguaje de corte soberanista - «espíritu monárquico", "principio regaliano"- modificar las costumbres que salvaguardaban la constitución patrimonial de la Corona castellana desde fines del siglo $\mathrm{xV}$, intentando de un modo despótico convertir sus virtudes políticas en derechos dominicales, y sacar provecho de la imagen que situaba a sus antecesores como origen de la constitución del territorio, leyendola en términos patrimoniales ${ }^{7}$.

5 Carta de la Princesa de los Ursinos a Torcy -6 de diciembre de 1705--, CoXE, W., Memorias de los reyes de España de la Casa de Borbón (1845). Madrid, p. 286.

6 AHN Estado leg. $673 / 1$ y 2 , leg. 736 . También BN Mss. 6774 y Mss. 10.919 «Reflexiones sobre el Estado presente de las cosas de Europa y esta Corte, con el motivo de la repartición de la Monarquía; descubrense las verdades en defensa de la inocencia perseguida, que la malicia ha tenido ocultas y otras circunstancias dignas de la común inteligencia", fines de 1700, pp. 97 a 118. Mignet, M., Négociations relatives à la Sucession d'Espagne sous Louis XIV (4. vols.). Paris, 1888-1892.

7 Vease sobre las distintas culturas políticas de ambas monarquías y sus consecuencias patrimoniales que dicha distancia conllevaba Astuti, G., La Formazione dello Stato Moderno. Turín, 1958; Barudio, G., La época del Absolutismo y la llustración 1648-1779. Madrid, 1986; NicollinI, U., La Propietá, II Principe e L'Espropiazione per Pubblica Utilità. Milán, 1952; KAISER, T. E., “Property, Soverignty, The Deciaration of the Rights of Man, and the tradicion of French Jurisprudence", Van Kley (ed.), French idea of freedom. The Old Regime and the Declaration of Rights of 1789. Stanford, 1994; KwASs, M., «A Kingdom of Taxpayers: State Formation, Privilege, and Political culture in eighteenth-Century France", en The Journal of Modern History, 70, june 1998, pp. 295/339. JAGO, CH. J., "Taxation and Political culture in Castile 1590-1640" en R.L. Kagan y G. Parker (eds.), Spain, Europe and the Atlantic World: Essays in honour of J.H. Elliott. Cambridge, 1995, pp. 49/72. Para la concreta coyuntura castellana Fernández Albaladejo, P., "La Monarquía de los Borbones" (1989), en Fragmentos de Monarquia. Madrid, 1992, pp. 353/454; VICENT, I. M., "Felipe V y la Monarquia Católica: una cuestión de «estilo»», en Espacio, Tiempo y Forma, Serie IV, 
Así pues asistimos a una conjura de infidelidades que obligó a reformular los criterios que forzaban a los castellanos a guardar fidelidad al Rey. También a repensar lo que tras este nombre de Rey debía contenerse tanto en cuanto a su persona política como en cuanto a su gobierno. Se trataba en el fondo de recordar, o al menos escribir bajo el pretexto de hacer memoria de lo que fue y debía seguir siendo, cuales eran las razones, los principios que fundaban la sociedad política, autodenominada Castilla, que como cabeza de la Monarquía Católica impregnaba con su estilo y sus principios de gobierno al conjunto de la misma. Principios que es necesario recordar no fundaban la obligación política en la representación, y por tanto no se manifestaban en la participación activa en el gobierno ${ }^{8}$, sino que encontraban su fundamento en un orden regulado por el mandato del amor confesionalmente estructurado por la dogmática católica desde la que se construía el legítimo ejercicio del poder político, tanto como se ordenaba el acceso al mismo ${ }^{9}$.

Al discutirse sobre cual de los dos reyes fuese el legítimo se acudía a los títulos que suponían dicha dignidad. Legitimidad de origen y de ejercicio cuya propia formulación suponía un repaso de los principios y los fines que fundamentaban la constitución política del reino, o al menos las razones que movian a sus distintos sujetos políticos, aunque de distinta constitución y relación entre si, a mantenerse fieles a una costumbre y a una persona que prefiguraba los compromisos que permitían la concurrencia de los diversos estados en la defensa del territorio, la Corte y sus instituciones. De ahí que los ataques a Felipe $V$, insistiesen en negarle el título de rey, presentandole como estatua o virrey ${ }^{10}$, por encarnar con su actuación otros principios y estilos: los de Francia. La fidelidad al Rey católico era la fidelidad a un estilo, a una constitución, a una virtud, a un ser propio, a un tiempo de gracia y providencia, no a una dinastía ${ }^{11 .}$

Madrid, 1994, pp. 397/423. VIEJO, J., «Domingo de Aguirre: la defensa de una constitución de libertade", en El Mundo Hispánico en el Siglo de las Luces. Madrid, 1995, pp. 1343/1348. Del mismo "Ausencia de política» en Monarquia, Imperio y Pueblos en la España Moderna, P. Férnandez Albaladejo (ed.), Alicante 1997, pp. 615-629.

8 DUnN, J., "The identity of the history of ideas", pp. 13/28 y «Political obligations and political possibilities", pp. 243/259 en Political obligation in its historical context. Essays in political theory. Cambridge, 1980.

9 IÑuRRitegui, J. M., "Monarquía y constitución», en Historiar, 1, 1999, pp. 8/18. Clavero, B., Antidora. Antropología Católica de la Economía moderna, 1991. Milán. Sobre dicha cultura en general HespanHa, A. M., "La Senda Amorosa del Derecho. Amor y justicia en el discurso jurídico moderno", en Pasiones del Jurista, Carlos Petit (ed.), Madrid, 1997, pp. 25 y ss. Del mismo "La economia de la Gracia" en La Gracia del Derecho. Economía de la cultura en la edad Moderna. Madrid, 1993, pp. 151/176 y "La Corte" en idem, pp. 177/202.

10 Fernández Albaladejo, P., "Rey Católico": gestación y metamorfosis de un título", en Continisio Ch. y Mozzarelli, C. (eds.), Repubblica e virtù. Roma, 1995, pp. 109-120.

"ViCENT, I. M., op. cit. 
Aunque fue en 1705 cuando el pleito sucesorio se comenzó a construir sobre la fidelidad y el cumplimiento de los compromisos adquiridos por los castellanos con su joven monarca, no sería hasta 1710-1711 que el debate cristalizó en lo que había de ser el discurso definitivo que saldaría los problemas de legitimación de la sucesión Borbón asegurando la fidelidad de sus vasallos sobre sus propios principios políticos, como demostró el fracaso de las reformas afrancesadas emprendidas, con la colaboración de Macanaz, por Orry, Robinet y Ursinos un año más tarde ${ }^{12}$.

Sin embargo, nuestra historia arranca unos años antes. A pesar de las sospechas de infidelidad y los intentos de asegurar la adhesión de los castellanos a Felipe $V{ }^{13}$, la gravedad de la situación no se puso de manifiesto hasta las derrotas que durante la campaña de 1706 acabaron con la salida de la Corte de Felipe V y la ocupación de Madrid durante algunos meses por los ejércitos aliados ${ }^{14}$. La posterior represión y persecución que el gobierno Borbón puso en marcha contra los castellanos "difidentes" ${ }^{15}$, que de una u otra forma se habían adherido al nuevo gobierno, o bien habían escondido sus afectos indecisos por qué partido tomar ${ }^{16}$, trajo a primer término el debate sobre la fidelidad. La dimensión del problema mucho más profundo y extendido de lo que las listas de procesados y presos

12 Martin Gaite, C., El proceso a Macanaz: historia de un empapelamiento (1969). Madrid, pp. 143 y ss.

${ }_{13}$ A raíz de una supuesta conspiración descubierta en 1704 se llegó a solicitar a los Grandes que prestasen un juramento de lealtad al rey; referido por Amelot en su carta de 26 de julio de 1705 dirigida a Luis XIV, AE Corr. Pol. (Esp.),147, fol. 288.

14 Los sucesos se decian habian servido para descubrir las auténticas intenciones de muchos "sebastianistas»: “Dizen, viene a rescatar/ a España de cautiverio; ... Ha venido a examinar/la fidelidad de España, ha venido por providencia del Cielo,/ para que se quite el velo/ a tanto traydor fingido/ ... a ponerle a nuestro Rey/ en sus manos los Traydores... Ha venido a verles dar/ el castigo merecido/ a todos, los que han querido/ contradezirle el Reynar: ... y mientras dure la Guerra/ avrá de esto gran partida» en BN, R. 60361, "El Viaje en Valde del Licenciado quien pensara, y venido de los Portugueses a Madrid", en verso, fols. 90-91v, Impreso en Sevilla, en diciembre de 1706 .

15 Aunque también pudiese aprovecharse la coyuntura para afirmar lo contrario como en estos versos que en el otoño de 1706 afirmaban la fidelidad de Castilla a Felipe $V$ intentando disipar sus temores: “Acaba Príncipe invicto,/ de descansar en tu trono,/ de estimar a la Grandeza,/ mirad que son leales todos./ Repara que las Castillas,/ te han defendido en todo,/ que quedandose desnudos/te dan su corazón propio» en BN Mss. 10.907, "Romance de los ciegos de Madrid a nro Rey y Sr Don Phelipe V que Dios guarde muchos años", fol. $182 \mathrm{v}$.

16 Macanaz to presentaría como un caso natural: "en una guerra civil hay siempre partidos. Los dos principales son los que están en disputa, y el tercero el que se mantiene pacífico o imparcial, aguardando el fin del suceso" en "Noticias particulares para la Historia Política de España. Dialogo político entre Rutelio y Clautino, calvinistas. Casos memorables de sus Reyes; en que se contradicen las opiniones fútiles de algunos graves Autores; dandose noticias ciertas de muchos sucesos; que hasta hoy son ignorados en nuestra historia", por Don MELCHOA DE MACANAZ, Pau, 26 agosto 1744, en Semanario Erudito, t. XIII, p. 194. 
demuestra ${ }^{17}$, desplazó la discusión pronto fuera de las salas de los tribunales trascendiendo en sus términos su estricto y erudito marco jurídico, desparramandose por las calles de las principales ciudades castellanas ${ }^{18}$, donde se contaminó con la polémica sobre la dudosa legitimidad que Felipe $V$ arrastraba desde su llegada a la Corte ${ }^{19}$. Polémica que los desafueros cometidos por su gobierno hasta ese momento no habian hecho más que avivar ${ }^{20}$. La coyuntura bélica ${ }^{21}$ había sido aprovechada por el ministerio francés para introducir las reformas hacendísticas y administrativas que, fundamentadas en una relectura en clave despótica ${ }^{22}$ de la constitución patrimonial del reino, debian permitirle aplicar una agresiva política de intervención en las haciendas señoriales y eclesiásticas ${ }^{23}$ que pusiese a su disposición los tesoros mejor guardados de la Monarquía en palacios, catedrales, villas, oficios o rentas. Además, la conexión directa que se establecía entre estas medidas y el éxito en la guerra, permitía criminalizar a quienes se resistían a ellas poniendo en duda su fidelidad a la causa Borbón.

Se trataba, entonces, tanto de saber quienes eran fieles, como de averiguar por qué y a quién o a qué debían de serlo. Los muy cuestionables títulos que habían llevado a Felipe $V$ hasta el trono, no parecían ya suficientes para decidir la voluntad de los castellanos a su favor. Para decidir su dudosa fidelidad. Sin embargo la presencia de tropas aliadas, en su

17 «Y aún en nuestra Castilla donde se hallan los ánimos tan divididos, que será muy singular la familia que no tenga el crédito de tener un afecto a la Augustisima Casa" en BN, Mss. 6680, "Demostración que hace un Español en defensa del Manifiesto del Sereníssimo Señor Don Carios III de Austria” (1708), fols. 9-40.

18 En este reino del disimulo en que se convirtió Castilla si unos se quejaban de que «en ningún tiempo se halló más opresa la razón, las leyes, y la libertad española que en la presente; pues no es licito hablar, ni discurrir y se ha pasado a atender los semblantes para adivinar los afectos" -en BN, Mss. 6680, "La verdad Cathólica contra un papel que con el nombre de desengaño Cathólico sea difundidc por DIDF», fols. 50-62-, los otros denunciaban «Los que aquí [en la infidelidad] concurren son tan avisados, que han hecho mucho estudio en no ser conocidos ..." -ibídem, "Consulta de un extranjero residente en Madrid a un Cortesano Político su Confidente y su Respuesta", fol. 206v-.

19 El debate puede seguirse a través de los documentos recogidos en Pérez PICAZO, M. T., La Publicística Española en la Guerra de Sucesión, vol. II. Madrid, 1966.

20 VICENY, I. M., op. cit.

2i Nicolini, U., La propietà, op. cit, pp. 91 y ss.

22 VIEJO, J., “Domingo de Aguirre", op. cit. Fernández Albaladejo, P., "La Monarquía de los Borbones», op. cit., pp. 353 y ss. BARuDio, G., «Zwischen Despotismus und Despotismus: Politische ideen in frankreich 1614-1685", en Pipers Handbuch der politischen ldeen, vol. 3, neuzeit: Von den konfessionskriegen bis zur Aufiklärung. Munich-Zurich, 1985, pp. 201 y ss. RowEN, H. H., The King's State. Propietary Dynasticism in Early Modern France (1980). New Yersey, 93 y ss.

${ }_{23}$ VICENT, I. M., "La Junta de Incorporación: lealtad y propiedad en la monarquía borbóni-

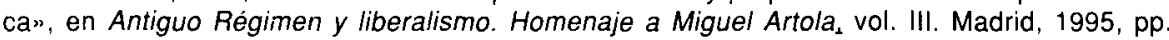
365-378. 
mayoría inglesas y holandesas, sobre la Península imprimió un giro radical al discurso político con que hasta ese momento se defendían los derechos dinásticos de ambos candidatos. Como explicaba cierta representación dirigida a la reina Maria Luisa, entonces, más por católica que por reina, porque "antes de que V.M. fuesse Reyna del mundo, era ya Vasalla de Christo" ${ }^{24}$, en está nueva coyuntura no peligraba sólo el trono de su esposo sino la propia Iglesia; pues «el Señor Archiduque emprende esta Conquista ...con sólas las armas de Olanda y Inglaterra. [y] en todas las ciudades que conquistan, quedan Governadores ingleses, u Olandeses, Enemigos de la Fe Católica ... [cuya] intención ...en esta guerra, es introducir, a espaldas del poder, su Religión». La conclusión era evidente, la guerra, al menos para los católicos, todos en la Monarquía, había dejado de ser por la sucesión, convirtiendose en "Guerra de Religión". El interés dinástico o las razones de estado, debían ceder su lugar en el discurso político a las razónes de religión.

Así pues, la presencia en la Península de herejes forzó, desde la cultura política hispana, la reformulación del conflicto en términos de religión, como ya se había sugerido durante la revuelta catalana, aunque entonces los herejes fueran otros ${ }^{25}$. El discurso político adoptaría, a partir de entonces, un lenguaje providencialista donde contaban antes que los derechos las virtudes de los contendientes, y no precisamente las cívicas, sino las teologales. Por eso lo que se reclamaba a la reina no eran armas sino teólogos: "Como Católica más que como Reyna mande V.M. que sus Teólogos se junten". Pero en este contexto la fidelidad o deslealtad a la casa de Borbón cobraba una nueva dimensión, no era ya un asunto de justicia sino de conciencia. Cualquier consideración hacía la justicia que pudiera contener la causa del Archiduque quedaba fuera de lugar, la nueva situación parecía obligaba «a renunciar al bien de la justicia por el mayor de la religión, abandonando la

24 Informe a la Reyna $N{ }^{a} S^{a}$ del Estado y Condición de la guerra, con que las armas enemigas de ambas Magestades Divina y Humana intentan la ruina de España por los Paises rebeldes de Cataluña y Valencia, por Fr. Gerónimo BELUIS y ESCRIBA, Jerónimo, Catedrático de Vísperas en Sigüenza, electo de Prima en Salamanca, Predicador del Rey y Prior de San Miguel de los Reyes de Valencia; impreso en Pamplona, concluido el 10 de mayo de 1706, pp. 35-38.

25 De semejante operación ya existían precedentes recientes en la misma Monarquía, a propósito, en este caso, de la rebelión catalana y los "franceses ateístas" que la apoyaban, para que así los vasallos acudieran a auxiliar con sus personas y sus bienes al Rey, impelidos por dicha obligación en conciencia que los clérigos debían impulsar: "Las Batallas en que oy está empeñada España, son propiamente de Dios, porque son por causa de Religión»... «mientras el Sacro Imperio estuviere en la Casa de Austria, tendrá la Fe un muro diamantino contra las puertas del Infierno ...el continuallas nuestro Principe, no es tanto ponerse de parte de los pundonores de su Corona, sino de la conservación de la Religión, que peligra notoriamente, entre ejércitos metalados de hereges de diversas sectas, si bien que militan banderas de un Rey Christianíssimo", Conservación de Monarquias, Religiosa y Política, por Fr. Francisco EnRíuez DE LA MERCED; fols, 3v-4v. 
probable justicia que al Trono Hispano tuviera la casa de Austria, por el seguro riesgo en que ponemos a la Iglesia con dicha concurrencia" ${ }^{26}$. A la teología correspondía la ardua tarea de someter el interés de los «políticos", convenciendoles de que en tales circunstancias, la infidelidad a Felipe V, lo era primero a Dios. Convenciendoles de la imposibilidad de "asegurar las conciencias de los que fomentan, ayudan, y desean, esta conquista con las Armas Enemigas de la Fe Católica” por muy justa que fuese su causa. Dichas razones debían conquistar las voluntades de los españoles, fortaleciendo su virtud y justificando sus conciencias, porque como bien decían «los Hereges esta es guerra de voluntades, y conquista de corazones: porque los corazones de los malos Vasallos la llaman: y las voluntades de los Rebeldes la fomentan» que si no «hubiera en España tan malos vasallos del Rey, no vieramos en sus dominios tantos sacrilegios contra Dios" ${ }^{27}$. La fidelidad pasaba a si de ser un compromiso civil o político a convertirse en un vínculo de graves consecuencias morales. En la fidelidad así entendida se articulaban dos mundos, dos virtudes: la política y la religiosa. Eligiendo entre Carlos y Felipe no sólo se estaba optando por un rey y una dinastía, ni sólo se jugaba la fortuna de un linaje, una ciudad, un estado nobiliar o eclesiástico, sino también el destino de un alma, y esta particular.

El debate, por tanto, no era ya entre felipistas y austracistas, sino entre teólogos y "políticos» ${ }^{28}$. Estos últimos intentaban escapar del pecado de infidelidad descubierto por los primeros abstrayendo "el reynar de la Religión, y la razón de Estado, de la Fe de Christo: ...diziendo: que lo que en esta guerra, circunstanciada de tan fea nota, se procura, no es el daño del error, sino el provecho del poder; porque no se desean las armas enemigas, con el fin de arruinar la Iglesia, sino sola [sic] su Potencia, ...todo lo que se obra contra la Religión, es muy fuera de la voluntad de quien coopera, o incluye a este fin» ${ }^{29}$. La polémica escapaba así por completo de los trillados senderos de la política o la jurisprudencia, para discurrir por los laberintos de la filosofía moral y su casuistica. Las distinciones entre consecuencias directas o indirectas, el obrar per sé y per accidens y otras, inundarían el nudo de los escritos más avisados que intentaban ligar o desligar la fidelidad o infidelidad a Felipe $V$ del confesionario. El discurso político se veía desplazado por la instrucción de conciencias.

26 Ibidern, fols, $14-16$.

27 Ibidem, fol. $16 \mathrm{v}$.

${ }^{28}$ RUBinsteIn, N., "The history of the word politicus in early-modern Europe", A. Pagden (ed.), The Language of Political Theory in Early-Modern Europe. Cambridge, 1987, pp. 41-56. INURRITEGuI, J. M. La Gracia y la República. El lenguaje político de la teologia católica y el "Principe Cristiano" de Pedro de Rivadeneyra. Madrid, 1998, pp. 111 y ss.

${ }^{29}$ Informe a la Reyna N. ${ }^{a} .^{2}$ del Estado y Condición de la guerra, fol. 38. 
Llegados a este punto no debe estrañarnos la relevancia que alcanzaron los confesores en este paisaje. Desde el confesionario se gobernaban las conciencias, guardianes del alma y dueñas de las voluntades. Los confesores administraban la única obligación a la que los españoles se sujetaban sin excepción: la de conciencia. Así pues, en esta particular batalla por ias voluntades, los confesionarios se convirtieron en las plazas fuertes cuyo dominio se hacía imprescindible si se quería alcanzar la victoria. No es de extrañar pues, que el Arzobispo de Zaragoza señalara a estos como fuentes de sedición: «Estoy informado de que gran parte de estas sediciones se han fraguado en los confesionarios" ${ }^{30}$. El antídoto que recomendaba contra semejante desastre, pasaba por disciplinar a los confesores con edictos de los obispos para los diocesanos y del Santo Oficio para los regulares «para que abrán los ojos a la luz de la Fe los que los tienen cerrados al conocimiento de la fidelidad debida a entrambas Magestades". Para ser coherentes dichos supuestos se estiraron hasta llegar a negar la absolución a quienes no confesasen su infidelidad, identificándose de esta forma la Iglesia con la causa borbón, al dejar fuera de sus limites - sus sacramentos- a quienes no se declarasen por el Anjou ${ }^{31}$. Se planteaba una persecución confesional de la fidelidad.

Sin embargo, la polémica no quedaba circunscrita al ámbito eclesiástico o académico. Los planfletos y papeles de mayor o menor enjundía que circularon durante toda la guerra, se expresaban en el mismo lenguaje, si bien traducido, frecuentemente, a formas y planteamientos más asequibles. Lo que no necesitaba explicación era el marco religioso general en que se había subsumido el enfrentamiento: católicos frente a herejes ${ }^{32}$. Las disgresiones y distinciones propias de la filosofía moral, quedaban aquí relegadas al olvido optándose por llevar hasta sus últimas consecuencias los supuestos confesionales de los que se partía. Las descripciones y prolijas

30 Carta del Arzobispo del Zaragoza al marqués de Mejorada de 26 de mayo de 1706 , BN Mss. 5.805; "Correspondencia entre el Marqués de Mexorada y el Arzobispo de Zaragoza", fols. 322-323.

31 "Que los Penitentes que llegan a recibir el Sacramento de la Penitencia, con el ánimo, y deseo de persistir en la infidelidad, así interior, como exterior son incapaces del efecto de el Sacramento, el que llega a él con ánimo de continuar la culpa, faltandole de esta suerte el propósito eficaz de la enmienda", J. Ferreras, Desengaño Cathólico, fol. 14. Y en el mismo sentido: “...porque la infidelidad es pecado mortal y es incapaz del efecto del sacramento el que llega a él con ánimo de continuar la culpa...Así los conocen los confesores y por eso les niegan la absolución", BN, Mss. 6680, Respuesta a un Papel, que con el nombre de Desengaño Cathólico se ha difundido por DJDF; fols.71-88 (1710-1711).

32 Como decia una sátira contra el Archiduque tras los sucesos de 1706: «Dicen que es redemptor nuestro/ que viene haciendo mercedes/a librarnos de los cristianos/y a cautibarnos de Herejes", en BN Mss. 10.907; "A la solemne entrada del Señor Archiduque en esta Corte", fols. $175-177 v$ 
enumeraciones de los sacrilegios cometidos por uno $\mathrm{u}$ otro bando, las profecías, revelaciones ${ }^{33}$ o exorcismos a endemoniados. Por este camino se llegaba incluso a emparentar al adversario no ya con el clásico Maquiavelo, sino en ocasiones también con el propio demonio ${ }^{34}$. Este reduccionismo simplificaba el problema amparandose bien en la bendición del Papa ${ }^{35}$, o en las actuaciones del Santo Tribunal de la Inquisición, únicas instancias institucionales y temporales de las que cabía esperar una declaración capaz de zanjar la polémica, y asegurar las conciencias. Aunque su seguridad también se discutiese introduciendo los distingos clásicos entre la potestad temporal y la espiritual, lo civil y lo canónico ${ }^{36}$, lo humano y lo divino ${ }^{37}$.

La vuelta de tuerca que suponía volver la guerra de religión no dejó de ser alentada por los hasta hacía poco "atheistas franceses», a los que correspondía ahora el papel de paladines de la razón católica, aunque sus pasadas y recientes azañas «políticas», entre las que cabía contar la pro-

${ }^{33}$ «...infinitas revelaciones de Dios a personas, sobre que debía reinar un Principe francés [una gran religiosa carmelita descalza; reconocimiento diplomático del papado; el Santo Oficio contra los Religiosos que tachasen de ilegítimo a Phelipe V]" Desengaño y seguridad las conciencias; Carta en que se consulta a un Doctor Theólogo sobre la zerteza que tiene el reynado de Phelipe V, Madrid, 16 de junio de 1712, pp. 327 y ss.

${ }_{34}$ «Que nos aseguró firmisimamente de que era Demonio, el que le havía revelado el Reyno a Carlos Tercero, dimos gracias a Dios ... al día siguiente confeso llamarse Luzbel, y venir en su compañia innumerables demonios con que quedo en esta Ynquisición preso el Demonio por sebastianista en la persona de este pobrecito y descubierto que quien aclama a Carlos tercero es el ynfierno y los Moustros de Tinieblas", BN Mss. 11.259/2; Carta de un sugeto de Murcia a su tio sobre punto de disidencia a Felipe $V, 1706$.

35 «Un hombre rústico de mi Patria me dixo: Padre para saber que debo guardar el juramento no he meneste Theólogos: pedile la razón y me dixo: el juramento se que se hizo, y lo sabe toda España; pero que sea malo yo no lo se, ni lo creere, sino lo dize el Santo Padre. Calzaba un oficial a un caballero en la Corte: este le preguntó que partido seguía? Respondió que al Señor Phelipe $V$ le dieron por Rey y que no estaba en su mano poner otro: fuele estrechando con algunas llusiones; y por último dixo el oficial: yo traere de mi Casa quien me defienda; fue a ella, y Bolvió con la Bula de la Cruzada y le dixo vea VS a quién trata como Rey de España el Papa. Pues yo el partido del Papa es el que sigo, este se VS con el partido que siguen los Hereges, si gusta», El Señor Phelipe $V$ es el Rey de las Españas verdadero, dado por la mano de Dios. Torre Incontrastable del segundo David perseguido y victorioso. Guarnecida de tres propugnaculos, lusticia Religión y Política de que pende mil escudos que defiende la Corona., por Fr. J. de AaAnaz, Pamplona, 1711, imprenta de F. A. de Neyra.

36 «El reconocimiento Pontifical como monarca temporal es susceptible de error ... el Papa no es infalible en el arbitraje de asuntos de derecho civil,porque no fue esa la misión que Cristo le encomendo para realizar en su nombre"; Desengaño y seguridad las conciencias; Carta en que se consulta a un Doctor Theólogo sobre la zerteza que tiene el reynado de Phelipe $V$, Madrid, 16 de junio de 1712, pp. 327 y ss.

37 Ibidem, «El Santo Tribunal es falible porque es humano ...por hacerse la averiguación con testigos, y testimonios particulares y humanos ...luego la sospecha en la fe contra el contesor, no nace de lo especifico o esencial de la Doctrina, o acción sino por el abuso del sacramento echo por el ministro mismo, como se ve en el que solicita a torpezas". 
pia elevación del duque de Anjou a rey Católico, les seguirían siendo echadas en cara por los austracistas durante el tiempo que duró la guerra. La nueva perspectiva para Francia tenía la virtud de despojar a la guerra de su apariencia particular, otorgándole una nueva dimensión universal, católica. No se jugaba ya la suerte de una dinastía sino la salvación temporal de una Monarquía, y la particular y eterna de cada uno de sus súbditos. Ligar la fe católica cuya defensa se encontraba en las propias raices de la constitución territorial e ideal de la monarquía ${ }^{38}$, a la que había acabado dando nombre, con la suerte de la dinastía que aspiraba a asentarse en su trono, era una operación que si bien rendía beneficios políticos y económicos evidentes, también engendraba compromisos que los «políticos" franceses no fueron capaces de discernir en un primer momento, dado que para los castellanos la fe religiosa seguía siendo principio y fin del gobierno político ${ }^{39}$.

Cuando al avanzar la contienda desapareció el peligro de que la herejía se generalizase por la Península, la ligazón establecida entre la sanción religiosa y la fidelidad dinástica perdió su primer y único fundamento. Sin herejes que expulsar la guerra y su razón ya no tenían porque construirse sobre religión. Las aguas debían volver a su cauce y la legitimidad de Felipe $V$ volvería a quedar en entredicho, con la guerra aún por resolver tanto en Europa como en España. Agotados los discursos formales de los justos títulos por muy dudosos, y neutralizados el juramento y la aclamación, la situación de Felipe $V$ resultaba muy débil ${ }^{40}$. La salida se fraguó gracias a la inercia que el clero había adquirido en la predicación de la necesidad moralmente obligatoria de permanecer leales a Felipe $V$, fuese cual fuese

38 ¿La Monarchía de España se puede considerar en el cuerpo mystico de la Iglesia como cuello ...1. . . ninguno más rendido a la cabeza de San Pedro y sus sucessores. Lo $2 .^{\circ}$ porque la obediencia a la Sede Apostólica es una de las leyes que estableció el Rey Don Alonso ...esta Monarchia dejaría de ser Cathólica y dejaria de ser España», J. de Aranaz: El Señor Phelipe V es el Rey de las Españas, op. cit.

39 “Otros Monarcas toman la Religión por estado de la conservación de sus Monarquías; pero el Católico haze de la Monarquia estado del aumento de la Religión ....Ningún Monarca ha sabido también cortar por el estado de su Monarquía con la tixera de la Fe, poniendola a los pies de la Religión como el Católico. En otras Monarquías fieles pretenden sus Principes de propósito las razones de su estado, y de camino la ruina de la Religión Católica que resulta de la fea confederación con tantos hereges [Francia]: pero en la España lo que directamente se pretende son logros, y augmentos de la Religión, conservar su pureza en los vasallos, y a esto viene accesorio el estado de la Monarquía" en Conservación de Monarquías, Religiosa y Política, por Fr. Francisco Enríquez de la Merced, (1648) Madrid, p. 17. En el mismo sentido P. Portocarrero, Theatro Monárchico de España que contiene las más puras, como cathólicas máximas de Estado, por las quales, assi los Principes, como las repúblicas aumentan y mantienen sus Dominios, y las causas que motivan su ruyna, (1700) ed. C. Sanz Ayan, Madrid, 1999.

40 Pérez Picazo, M. T., op. cit., vol. II, pp. 63 y ss. 
su justicia. La sin razón que suponía mantenerla una vez que habían desaparecido las causas que habían suscitado tan extraña alianza, cuyo mejor hallazgo era la conceptualización de la infelidad como pecado mortal, se suplieron torpemente. La sacramentalización de la fidelidad que hasta ese momento había tenido un caracter utilitarista, paso a convertirse en fin de si misma. Las razones que la sustentaban se hallaron resucitando los derechos y títulos que habían servido para revestir de cierta legitimidad su llegada al trono. Sus deficiencias no se cubririan con nuevos argumentos jurídicos o políticos sino con la propia sanción moral que se suponía ellos debían sostener. El inconsecuente silogismo que se defendía venía a decir así: I. No reconocer a Felipe $V$ como verdadero y legítimo rey de España siedole infiel es pecado. II. Es pecado porque por derecho divino, natural, de sangre, llamamiento, aclamación y juramento «devemos la obediencia a nuestor Rey y Sor Don Phelippe V» ${ }^{41}$. III. Y tales títulos son ahora suficientes porque no reconocerle por rey es pecado.

La inconsistencia de este discurso se sustanciaba en la afirmación de que «el que no ama, reverencia y obedece en lo justo a su legítimo Rey cuando la matería es grave, peca mortalmente: el señor Phelipe $V$ es legítimo Rey de España y los Españoles... " 42. Dicho postulado, que quintaesenciaba el discurso hispano construido en favor de Felipe $V$ al compas de la Guerra de Sucesión, se contenía en el primero de los tres Papeles que D.Juan de Ferreras escribiera en defensa de la legitimidad con que Felipe $\mathrm{V}$ ostentaba la Corona Hispana bajo el título genérico de Desengaños Cathólicos y sostenía cual dogma todo su argumento. Los discursos, con que intentaba apuntalar al Anjou en el corazón, la conciencia y el interés de los españoles tras los afortunados acontecimientos de 1710, acababaron por resultar contraproducentes. Con sus diatribas, el luego ilustre Párroco de San Andrés, consiguió al reanimar las brasas de los debates seudo jurídicos, políticos o morales en vez de asegurar a Felipe $V$ poner en evidencia la improbable justicia de su causa ${ }^{43}$.

Sus detractores, austracistas y felipistas por igual, demostraron que "el reinado de Phelipe $V$ no pertenece a Materia divina, con que asentimos a las verdades que Dios revela, no es por tanto causa de herejía" "44. Que

\footnotetext{
${ }^{41}$ BN Mss. 6.732; “Exortación de Don Francisco Pedro de Mendoza cura propio de la Estr. ${ }^{a}$ y examinador Sinodal deste Arzobispado a los trece lugares del curato", fols. 6 y 6 bis.

42 BN, Mss. 6680, Desengaño Cathólico, por don Juan de Ferreras cura de San Andrés de Madrid, fols. $45-48 \mathrm{v}$ (nov. 1710).

43 Salazar y Castro como censor desaconsejó la difusión del último de ellos, por la perjudicial polvareda que habian levantado sus antecesores.

44 Desengaño y seguridad las conciencias, op. cit., pp. 327 y ss.
} 
sus títulos eran muy dudosos, y que aunque no lo fueran tampoco podría deducirse de ellos ninguna responsabilidad moral práctica de no reconocerlos por tales ${ }^{45}$, porque "se es rey por ejercicio y consentimiento del Reino, que si te puso te puede quitar" de lo cual se deducía la inferencia de los títulos y seguridades alegadas ${ }^{46}$.

En ningún momento y por ningún camino se consiguió formalizar un discurso que comprometiese la voluntad de los castellanos. El discurso moral que a modo de constitución política ordenaba su conducta, y por cuya defensa pretendía Felipe $V$ estar luchando, permitió siempre preservar su libertad tanto en el plano teórico como en el real. La primera pieza sobre la que se intento construir la obligación política que los castellanos debían a Felipe $V$ por la cual debían permanecerle fieles fueron los títulos que sirvieron a éste para llegar hasta el trono de Madrid, en particular los que parecian comprometer de forma pública la voluntad de los castellanos: la aclamación y el juramento. Los otros, la sangre y sus renuncias, más el cuestionado testamento de Carlos II, nunca habian dejado de ser objeto de discusión incluso aún antes de morir este. Sin embargo pronto resultaron insuficientes para apuntalar la fidelidad castellana.

Tanto la aclamación como el juramento se presentaron como fruto del miedo que los castellanos tenían a las armas de Luis XIV, miedo que sólo se había disipado en parte con la llegada del ejército aliado a la Península. Así pues, la falta de libertad de quienes juraron lo dejaba sin efecto ${ }^{47}$. Si esto no fuera suficiente se explicaba, informado el argumento desde los principios de la filosofía moral, que ningún juramento por perfecto que fuese en su realización dejaba de estar supeditado al bien común. Si este

45 Ibidem, «...pero esto que tiene que ver para hacer verdad de fe el reinado de este hombre en particular ...si se le niega obediencia es negado el supuesto de que sea legítimo, niegale el verdadero derecho el reino, niegale la autoridad de mandar, niegale que la aceptación fuese legítima y por último niegale que el juramento fuese valido, lizito y así que no obliga".

46 lbidem.

47 «Para la revalidación de los juramentos Seo cura son necesarias cuatro cosas: Libertad, Verdad, Justicia y necesidad: ... si fueran hechos sin Libertad y contra Justicia no obligan ni valen; antes bien el sabio confesor debera aconsejar lo contrario que diremos pues del Juramento que se hizo a favor del Señor Felipe $V$ en que no hubo libertad porque concurrieron los diputados a él sin la solemnidad de las Cortes, en que la Majestad jura la indemnidad para que cada uno tenga libertad sin la opresión del miedo del castigo; Qué diremos de este Juramento que se hizo en tiempo en que su Majestad estaba hacía días en España inundada de tropas francesas? Qué diremos de un juramento en que los avisos fueron con precisión para que viniesen a jurarle Rey? Qué diremos de un Juramento, que es más que cierto, que si alguno le hubiera resistido hubiera sido su último aliento en un cadalso?", BN, Mss. 6680, "Aviso cristiano, Atalaya de la fee. Destierro de heréticas ignorancias contra el desengaño Cathólico del Cura de S. Andrés", fols. 63-70 $(1710-11)$. 
se viese comprometidodo por el cumplimiento de aquel debía seguirse el ejemplo del rey David: "Ni el juramento que hicimos de fidelidad a su Alteza de Anjou, pudo hacerse, ni subsistir en su fuerza y vigor; porque el proceder siniestro de S M Cristianísima y de todos los ministros que son arbitros de esta monarquía, y el mal tan grande que de observar este juramento se sigue ...preferir este juramento a otro más fuerte, que tenemos de conservar en paz, y mirar el bien común de la República. La Decretal dice: no ha de ser el Juramento de los Reyes (lo mismo se entiende del Juramento de los Vasallos) vínculo para lo injusto, sino esfuerzo para adelantar la Justicia. Por esto fue condenada la acción de Saul que por cumplir lo prometido a Agab ...sustentó la injusticia; y al contrario fue alabado David porque no cumplió el juramento o promesa en favor de Naban" ${ }^{48}$. En este caso bastaba comparar la imagen de Rey Católico y virtud que figuraba la Monarquía hispana, como imagen del bien común con la política francesa que la tradición literaria hispana enseñaba para demostrar lo tiránico, embaucador, maquiavélico y, en fin, endemoniado que era el gobierno de Francia que encarnaba la Casa de Borbón, y lo lejos que estaba de poder representar bien común alguno. Los sacrilegios y enormidades cometidos por sus soldados durante la guerra en Castilla, y el despotismo con que su gobierno se comportaba, además del yugo con que intentaba someter a la Iglesia y le había llevado a romper con Roma, no eran más que algunos de los más recientes ejemplos y argumentos a los que se sumaban las prisiones y destierros injustos cometidos. Todo ello avalaba la injusticia de sujetar la voluntad a un juramento fuente de tanta desdicha.

En la postrimerías de la guerra, eliminada la amenaza que los hereges habian supuesto, desaparecian los motivos que habían confesionalizado el discurso político hispano. Los dudosos títulos en que se habia apoyado el ascenso al trono de Felipe $V$ conservaban intactos todos sus defectos. De su triunfo no dependía ya la conservación de la Iglesia; su causa, por tanto, había dejado de ser la de Dios. Ni siquiera su prolongada posesión del cetro podía alegarse como título, porque nadie podía pretender que hubiese sido pacífica. Los discursos, vestigios del inmediato pasado que llevados por la inercía seguían vinculando la fidelidad hacia Felipe $V$ con un deber moral debían ser reprimidos. La extensa instrucción títulada Desengaño y seguridad de conciencias publicada en 1712 no perseguía otro objetivo que desamueblar las conciencias católicas del mobi-

48 Demostración que hace un Español en defensa del Manifiesto del Serenissimo Señor Don Carlos III de Austria, fols. 9-40, (1708). 
liario dinástico que habían adquirido durante la pasada guerra ${ }^{49}$. Predicaciones - como la que había sugerido tal disgresión- en que se afirmaba faltar a la fe divina si no se tenía a Felipe $V$ «por verdadero rey» debían ser desterradas.

El vacío que dejo la explicación de la guerra en términos confesionales, una vez cumplida su principal fin, la salvaguarda de la católicidad de la Monarquía, fue cubierto por la floración de dos discursos surgidos al compas del conflicto, que ahora pasaron a un primer plano. El primero de ellos tenia por misión paliar los efectos que la moralización de la obligación política habían tenido. Por una parte rescataba de las Partidas el discurso libertario de la fidelidad feudal y el segundo fortalecía el discurso legitimador de providencia y virtud. Con el primero se frenaba el impetu decisionista del monarca, impidiendo la persecución de los partidarios del archiduque, y afirmando la libertad de los señores castellanos en su relación con un Felipe $V$. $Y$ con el segundo se daban razones para conservar su trono más alla de cualquier duda.

Se defendía así el derecho de los castellanos a elegir el candidato que en buena conciencia, es decir, en persecución del bien común, les pareciese el legítimo Rey. Sin embargo, dicha libertad no era defendida en términos civiles sino feudales. Se recurría a las Partidas para demostrar que no se pecaba por elegir a uno u otro Señor, siempre que no se hiciese guerra al natural, atribución que ninguno de los dos candidatos podía pretender más que como posibilidad probable. Ni siquiera se merecía castigo el que errase en la elección del que luego hubiese de resultar vencedor, siempre que se hubiere mantenido fiel al que libremente escogió. Así pues, en virtud de esta antigua libertad feudal era lícito al vasallo tomar por Señor al que creyese con mejor derecho para llamarse Rey. En otra vertiente de esta misma composición se defendía el derecho de abandonar al Señor, Rey o no, si este le hubiese perjudicado, siempre que el agravio procediese de su persona y no de su oficio real ${ }^{50}$.

49 "Señor, oyendo predicar del Santísimo a un religioso ...que el español que no tenía por verdadero rey a Phelipe $V$ faltaba a la fe (divina) ...esto no es conveniente ni prudente predicarlo de materia tan controvertida ... toque la materia en junta de hombres sabios ...y los hallé tan temidos de este dictamén ...", BN Mss. 2569; Desengaño y seguridad las conciencias, 1712, pp. 327 y ss.

50 "...el Rey debe defender y honrrar al vasallo como a hijo en su distinción y grado ... De que es disculpable, que aquel que injustamente se halla despojado de sus conveniencias o hacienda por el Rey, desee otro rey Justo; y que son libres los vasallos en España para poder mudar domicilios y irse a donde juzgan mayor combeniencia: omitense los textos ad municipalem. Y supuesto que el Pontifice a declarado por justa la pretensión del Señor Carlos III, y que su sentencia es de juez privativo ...que sin pecar podrán los españoles ir a ayudar la causa del Señor Carlos III conformandose con el dictamen del Vicario de Cristo, y que los Católicos confesores podrán absol- 
El principio que marcaba la obligada fidelidad era de un probabilismo casi absoluto, y venía a conformarse por completo con la actitud que la mayor parte de los castellanos guardaron durante casi toda la guerra. La afirmación que nadie discutía, aunque algunos la contradijesen en el curso de sus apasionados alegatos de forma inconsecuente e inconsciente, era la de que se debía ser fiel con la voluntad aunque no necesariamente de corazón a aquel que en tu terriorio tuviese el poder. Dejando siempre a salvo la posibilidad de abandonar el territorio como medio cierto de liberarse de la obligación hacia el señor del mismo. Esta doctrina que los polemistas arrancaban desde Santo Tomás y asentaban en Partidas volvía totalmente irrelevante el derecho que tuviesen Felipe o Carlos al trono, por lo que a sus vasallos importaba. Es más, tampoco el ejercicio que hiciesen de su oficio, puesto que dicha doctrina se completaba con los discursos acerca de la Providencia de Dios y la santa tribulación ${ }^{51}$ que salvaban la contradicción que suponía el someterse a un rey aunque este fuese tirano ${ }^{52}$ o el padecer una guerra injusta. Solo quedaba en tal caso confiarse a la oración y esperar que Dios dispusiese el cómo, el cuando y el donde para el fin de tal gobierno, ya que la obligación política no encontraba en semejante situación otro fundamento que la voluntad divina ${ }^{53}$.

verlos sin buscarles esta escambronera de conciencias... La verdad se sujeta siempre a lo que hubiere declarado o declare la Romana Sede y a su corrección ...". Aviso cristiano, Atalaya de la fee. Destierro de heréticas ignorancias contra el desengaño Cathólico del Cura de S. Andrés, fol. 67.

51 «Embiar Dios las guerras que en estos tiempos fatigan a España, no es tanto castigo de culpas quanto exercicio de virtudes. ...estos males que padeceis de hereges e infieles ...no los embía Dios por castigaros, sino que assí provados y acrisolados en el horno de la tribulación, luzca con mayores esplendores vuestra fidelidad a Dios ...no nos quiere castigar Dios por este camino, quanto enmendarnos, no es multa tanto de pecadores, quanto acicate de justos ...[la guerra] ocasión de muchas virtudes ... siempre has de tener enemigos con quien batallar", fols. $5 \mathrm{v}-6 \mathrm{v}$., fol 17.

52 Para este caso debian contemplarse "dos razones en cada Vasallo del Rey, porque se deve mirar como Vasallo del Rey, y como miembro de la República; y aunque en este caso de ser Rey tirano, e intruso, no tuiera impedimento, por la razón de Vasallo, para contribuir, y fomentar el que le quitassen la Corona, a quien injustamente la posseía, para darla a quien de derecho le tocava; pero como miembro de la Republica devía mirar por ella, y no ocasionar los daños de las extorsiones que indispensablemente se siguen a estos trastornos; de quitar un Rey, y poner otro, de forma que pecara el que contribuyera en este caso, a introducir en la Corona al que de derecho le

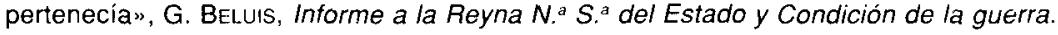

${ }^{53}$ “....porque el mal Rey lo pone Dios con su alta sabiduría incomprensible en sus juicios ...luego si Dios pone los Reyes tiranos por castigo de los pecados de los pueblos, y si su potestad es de Dios por su ira, debemos obedecerlos y reverenciarlos con humildad ... así aconseja que a falta de superior a quien recurrir recurran a Dios con oraciones y penitencias, que tiene el corazón del Rey en su mano (Prov. 12) ...podrá convertir al tirano cuando convenga ...con que queda asentado que en la doctrina apostólica se debe obedecer al tirano puesto en la potestad de Rey, y sin distinción de legítimo o ilegítimo ... se ve que el amor al Rey se le deve por precepto divino como a prójimo y la obediencia como a Padre por el $4 .^{\circ}$ precepto ...como no se oponga a la ley divina lo que mandaré", BN, Mss. 6680, "La verdad Cathólica contra un papel que con el nombre de desengaño Cathólico sea difundido por DIDF" (1710-1711), fols. 50-62. 
Esto, por otra parte, se compadecía con la actitud que los castellanos habían seguido desde el comienzo del drama, aún antes de que muriese Carlos II, a la llegada de Felipe V, ante sus primeras "novedades", y cuando la guerra alcanzó la Península. Entonces como se explicaba al fogoso $\mathrm{Fe}$ rreras en 1711, no era asunto de derechos o confesiones ya que el pleito sucesorio estaba en el campo de batalla y la decisión de las armas estaba confiada al juicio de Dios. Las tensiones, amenazas y despojos de la guerra que pretendían ganar para una u otra dinastía la fidelidad castellana, no habian conseguido desgajarla de los principios y credos que organizaban su república en torno a su virtud católica.

La sustancia conciliadora de este discurso que estructurado desde los principios de una filosofía moral que descansaba en último término en la sabiduría divina, constituían también la razón del Consejo para ejercer el gobierno y la justicia. Los mismos principios y los mismos tópicos conforman la consulta con la que el Consejo organizaba, dividia y exculpaba a la inmensa mayoria de los que Felipe $V$ quería castigar por traidores a su persona. Porque, como el Consejo explicaba, no podía el Rey imponer su voluntad sobre la razón que debía de dirigir el proceso que salvaguardaba al inocente tras los muros de la justicia. Los jueces eran meros administradores de la misma, no ejecutores de la voluntad real, y en el caso, que entonces se vislumbraba de que ambas instancias entrasen en conflicto, antes debían abandonar sus oficios que traicionar la razón jurídica y moral que incorporaban, puesto que como apuntaba el Consejo si es efectivamente culpable aquel al que alcanza la sospecha pero no la prueba ya hará Dios con su providencia justicia de él.

Al final de la contienda, la fidelidad estaba decidida y comprometida. Había vencido el candidato de Dios. El discernimiento se hacía a posteriori. Las profecías, natalicios, muertes, y victorias milagrosas señalaban el camino de la voluntad de Dios que a lo largo de la guerra había disfrutado Felipe $\checkmark$ más que haberle favorecido o beneficiado, le habían bendecido a los ojos de su vasallos ${ }^{54}$. A partir de ese momento era Dios y su Providencia quien legitimaba a Felipe $V$. Otro discurso no cabia ${ }^{55}$. El resto de los títulos y de-

54 Fr. J. de Aranaz: El Señor Phelipe V; A. de Montanchez, Avisos Morales y Políticos para Principes, eclesiásticos y militares. Dedicados a el serenísimo Sr Luis Primero, Principe de Asturia, 1721; J. CABRera, Crisis Política determina el mas florido Imperio, y la mejor institución de Principies, y Ministros. Dedicada al Principe de Asturias D. Luis I, Madrid, 1719.

55 BN R/60361, «Relación diaria de lo sucedido en Madrid desde que el Rey N Sr llegó de la jornada de Cataluña, dia 6 de junio hasta el 7 de Agosto de 1706", publicado en Sevilla, fols. 80 83: "Sólo la fe viva de que Dios rectísimo Juez daría la sentencia por parte de la Justicia". 
rechos quedaron relegados a un segundo plano. Los castellanos fieles a Dios tenían por rey a Felipe. Las razones estaban desde hacía tiempo de más, como se recriminaba a Don Juan de Ferreras por su inoportuna e innecesaria alegación en los albores de 1711: «...Y si entiendes que Dios destino a Felipe $V$ para nuestro Monarca, para que alegas leyes, produces herencias y exageras aclamaciones? No es todo inútil al soberano poder de Dios que dispensa los Reyes sin atención a las reglas humanas» ${ }^{56}$.

Incluso el juramento piedra angular del discurso político que había pretendido asentar sobre bases jurídicas y civiles la obligación de permacer fieles a Felipe $\mathrm{V}$ al margen de consideraciones morales o escatológicas, quedaba subsumido en la lógica Providencialista que al presentarlo como un milagro lo convertía en signo inequívoco, uno más, de la elección divina: "Las señas son notorias pues aquella unión de voluntades al jurarle, con razón se atribuye al Imperio del primer Motor» 57.

De este modo y en este caso vemos como, el discurso de la fidelidad escapa de los círculos cortesanos donde los estudios sobre las redes clientelares lo vienen situando, recuperando su protagonismo constitucional en el discurso político. La singular coyuntura en que se encontraba la Monarquía Católica y su especial naturaleza puesta de manifiesto de forma irreversible tras su rechazo de los principios políticos secularizados sobre los que se firmaron los tratados de Wesfalia le brindaron dicha oportunidad ${ }^{58}$. La fidelidad vino así a ocupar el lugar central, convirtiendose en el concepto clave sobre el que se anudó el discurso de la obligación política en la Monarquía Católica durante la Guerra de Sucesión, dada la alternativa siempre presente entre el archiduque Carlos y el duque de Anjou de forma efectiva hasta mediados de 1711 y formal hasta la firma del Tratado de Viena en 1725.

BN R/60361, "Carta y Compendio de lo que ha sucedido en España desde el 10 de marzo de 1706 hasta el 18 de mayo de 1707 con algunas adiciones más que la primera escribe", fol. 126: "Servilleteros ...juntos en sus sinagogas ... a disputar el derecho de nro gran Rey; no haziendose cargo de que Dios lo quiere dueño de la Monarquía Española, como otro David, que sin tener el Derecho que le asiste y tiene nro Monarca, lo ungio Rey; pues lo tiene por muchas maneras".

56 BN, Mss. 6680, «Respuesta a un Papel, que con el nombre de Desengaño Cathólico se ha difundido por DJDF» fols.71-88, (1710-1711).

57 BN, Mss. 6680, "Consulta de un extranjero residente en Madrid a un Cortesano Político su Confidente y su Respuesta", fols. 206v-207v y 209-211. Similar operación se realizó con la aclamación: "11. ...fue aclamado y recibido por Rey de toda la Monarquía de España, es manifiesta; porque lo fue en los Reinos de Castilla, y Leon, Galicia, ...Milán, Flandes e Indias sin que en tantos reinos, y tan distantes ...haya habido alguno, que no le aclamase y le recibiese por Rey, Señal segurísima de que Dios le designo para Monarca de ella», Desengaño Cathólico; op. cit., fol. 47.

58 VIEJO, J., Ausencia de política, op. cit., pp. 15 y ss. 
La lectura del enfrentamiento en términos religiosos complicó el debate urdido en torno a la fidelidad, convocando diversos lenguajes - jurídico, religiosos, político ${ }^{59}$ - que dirigidos y jerarquizados desde una filosofía moral teologizada de corte católico acabarían por armonizar las distintas posturas que en Castilla se ofrecieron durante la guerra, evitando la ruptura de la convivencia y sentando las bases de un acuerdo político que legitimando a Felipe de Anjou, a la postre vencedor en España, como nuevo rey católico salvase las personas y los patrimonios de aquellos que por disentir con sus modos o por seguir al Archiduque habían sido excluidos, vejados o perseguidos en algún momento de la contienda. Dicho desencuentro, además de significativo de la auténtica naturaleza de la monarquía y del conflicto que entonces se ventiló so capa de guerra dinástica, definiría en su resultado los límites por los que habrían de discurir las reformas que tanto los ministros de Felipe $\mathrm{V}$ como las que sus sucesores intentaron poner en marcha.

Todo ello nos debe permitir resituar al menos para nuestro caso el problema de la fidelidad, enmarcandolo en una perspectiva constitucional extraña a los trabajos que se ocupan de ella en la baja edad moderna. EI tema es abordado por la más reciente historiografía tanto anglosajona como continental en relación al estudio de los sistemas clientelares que organizaban la cambiante vida cortesana de sus monarquías ${ }^{60}$. La fidelidad política, no particular, al monarca, o a los principios que informaban el orden patrimonial, moral y jurídico de los Reinos se obvia como algo obsoleto. La fidelidad no aparece como uno de los problemas desde los que abordar la constitución política de las Monarquías o nuevas Repúblicas, sino como un asunto ligado irremisiblemente ya a las relaciones privadas entre los individuos que componen sociedades constituidas, bien sobre el principio dinástico o bien sobre los mimbres contractuales tejidos por la nueva filosofía política que recrea el viejo iusnaturalismo sobre nuevos principios en Inglaterra, Países Bajos y los territorios más septentrionales del Imperio.

De este modo uno de los primeros objetivos de parte de la historiografía ocupada en descubrir y describir la influencia que las fidelidades per-

59 Pocock, J.G.A., “Languages and their implications: The transformation of study of political though", Politics, Language \& Time. Essays on political Thought and History. Chicago, 1989, pp. 3-41. PAgDen, A., "Introduccion", The Language of Political Theory, op. cit., pp. 1-17.

60 Una visión global en Sh. Ketteaing, J. Russell Major and A. Jouanna, "Patronage, Language, and Political Culture», French Historical Studies, 17, (1992); pp. 839-881. Una puesta al día en Hermann, A. L., "The Language of Fidelity in Early Modern France", The Journal of Modern History 67(1995); pp. 1-24. 
sonales y familiares tenían durante las postrimerias del siglo xvı y sobre todo el XVII europeo ha sido el desligar dicha realidad de los prejuicios que hoy califican dichas actitudes con la corrupción política, demostrando su caracter estructural y su integración lógica en una cultura diversa a la nuestra y desde la que dichos comportamientos no sólo eran legítimos sino necesarios no sólo en la sociedad sino también en la Corte e incluso la justicia ${ }^{61}$.

Más allá de los contextos y circunstancias particulares que empujaron a la fidelidad al centro del dircurso político durante la Guerra de Sucesiòn en Castilla, su situación debe reconocerse como fundamental aunque eso si escondida. La inexistencia de un distinción real entre público y privado, y la ubicación de la fidelidad como un fruto, el principal, de la amistad ${ }^{62}$, principio primero de las sociedades precontractualistas, revela el caracter sistémico que dicha obligación tenía en la estructura política de las mismas.

Sin negar la pujanza que el iusnaturalimo británico estaba alcanzando a fines del XVII y comienzos del XVIII al servico de los valores del mercado, parece aventurado aún para discernir dicho discurso, prescindir de los fundamentos feudales y religiosos que habian cimentado las monarquías que aún gobernaban Europa, aunque su principios legitimadores se hallasen sometidos a revisión en casi todas partes desde los albores de la Edad Moderna.

La peculiar situación de la Monarquía Hispana, como antes apuntabamos, aferrada a un discurso político confesional católico que si bien en un principio la había permitido autodefinirse ad extra como un conjunto territorial légitimo y coherente en si mismo, la había terminado por aislar a raiz de su autoexclusiòn de los principios a partir de los que se había acordado la Paz de Westfalia ${ }^{63}$. Dicha situación marginal hizo posible que la crisis dinástica que vivió a raíz de la muerte de Carlos II y la posterior entrada de las tropas aliadas en la Península a partir de 1704 hiciesen florecer un discurso de cuño constitucional en el que la fidelidad ocupaba un lugar central, como primer y único concepto sobre el que construir una obligación política comprometida no sólo con uno de los candidatos que se

61 Kettering, Sh., “Patrons, Brokers, and Clients in Seventeenth-Century France, "Gift-giving and Patronage in Early Modern France"”, French History, 2 (1988), pp. 131-151. HeSpanHA, A. M., «La economia de la gracia», La Gracia del Derecho. Madrid, 1993, pp. 151-176. Clavero, B., Antidora, op. cit.

62 B. Clavero, Antidora, op. cit.

63 Pagden, A., "Fede pubblica" y "fede privada": confianza y honor en el Nápoles español”, El imperialismo Fspañol y la imaginación politica, Madrid, 1991, pp. 107-142. 
disputaban el trono sino antes que nada con el bien común ${ }^{64}$. Una fidelidad que lo era sobre todo a una virtud que aunque de consecuencias civiles y políticas era toda religiosa tanto en sus principios como en su contenido y fin último ${ }^{65}$. Hasta tal punto que este bien común, al que debían supeditarse aún los juramentos, tenía por fin la conservación de la Monarquía.

La fidelidad era el nexo sagrado que ponía en conexión dos espacios el político y el religioso, pero también dos tiempos uno humano y otro eterno. Por eso la elección entre austrias o borbones además de un dilema político, era un problema moral. Ubicada la disyuntiva dinástica en un tiempo de dimensiones escatológicas, gobernado por la Providencia Divina ${ }^{66}$, más que de elegir se trataba de discernir en los signos de los tiempos sobre qué candidato recaería el favor divino ${ }^{67}$. Los castellanos en su dimensión temporal, corporal, podían elegir el que más favoreciese sus interéses personales $o$ el que creyesen ayudaría a conservar o aumentar la Monarquía; o mejor, dado el trance, a restaurarla. Pero como almas dicho juicio carecía en absoluto de valor, puesto que era axioma de la cultura política castellana, recordado oportunamente en los límites del reinado de Carlos II por el Cardenal Portocarrero, que el destino de las cosas humanas no se sujetaba a razones o virtudes civiles sino a la vo-

64 «Todos tienen puesta la mira en su interés, y el propio a dispuesto la divina Providencia no se separe de el común, debe preocupar primero la atención y después de esto el particular conociendo todos, que la conveniencia y utilidad común, no puede dexar de redundar en el particular" con lo cual J. Ferreras en su Desengaño Político, no estaba predicando economia politica, sino caridad cristiana.

65 INUnRltegul, J. M., La Gracia y la república, op. cit. Pocock, J. G. A., The Machiavellian Moment. Florentine Political Thought and the Atlantic Republican Tradition. Princeton, 1975, pp. 3-79.

66 Pocock, J. G. A., The Machiavellian Moment, op. cit. Del mismo, para un ámbito confesional distinto pero contemporáneo en el tiempo y parecido conflicto "Conservative Enlightenment and Democratic revolutions: The American and French Cases in British Perspective" en Gover. ment and opposition, 24, (1989), pp. 81 y ss. y "The Fourth English Civil War: Dissolution, desertion and Alternative histories in the Glorius Revolution" en idem, 23 (1988), pp. 151 y ss.

67 En dicha clave se expresaban unos versos contra la continuación de la guerra por parte de los aliados y quienes les apoyaban en la Corte: "Sebastianistas ciegos ... Hasta quando vuestras lenguas/ cortadas a lo moderno, ... Hasta quando vuestras plumas,/ con los Luteranos buelos,

No basta ver los prodigios, con que esta explicando el Cielo/ que Felipe Quinto tiene la justicia, y el derecho? ... serán estos argumentos,/ de que es voluntad de Dios,/ que Filipo tenga el cetro./ vosotros quereis que sea/ medida vuestro desseo/ de la voluntad de Dios/y assi aplicais los sucesos/...Será voluntad de Dios/ qe se falte al juramento de lealtad, que los vasallos/ a este Principe le hicieron? ... Sin duda que imaginais/ que nuestro Monarca Excelso/ no tiene quien le defienda, / porque ay quatro malcontentos./ Jesús que disparate. Pues con tener a su Abuelo, tiene fuerças para dar / guerra a todo el mundo entero ...en donde en cada vasallo [Castilla]/ tiene el Rey un Polifemo./ Dexo a un lado algunos pocos/ que vosostros, que protervos,/ $\sin$ Dios, $\operatorname{Sin}$ Ley, ni conciencia,/estais escupiendo al Cielo.", BN, R. 60361, "El desengaño a cargas conducido a los Sebastianistas por Requa de Juan Harriero", fols. 92-95. 
luntad de Dios, único que podía hacer dichoso a un hombre y grande a una Monarquía.

Lo dicho hasta aqui no significa que estemos ante un discurso político unívoco, pero si ante un único universo cultural en que lo religioso aparecía antes o después, por exclusión o dedicación, como determinante. De ello era responsable la propia identidad forjada en el último siglo y medio de la Monarquía que se hallaba en juego, pues sí bajo su gobierno concurrían flamencos, castellanos, aragoneses u napolítanos, con sus respectivos derechos, culturas y lenguas, e incluso intereses diversos, todos compartían una única conciencia, la católica, fuente de sus pretensiones universales y prisión de su cultura política. 